\title{
A Rare Case of Interlobar Pneumothorax
}

\author{
Serbeze Kabashi-Muçaj ${ }^{1,2}$, Jeton Shatri ${ }^{1,2 *}$, Kreshnike Dedushi-Hoti ${ }^{1,2}$, Hakif Thaqi ${ }^{2}$, Flaka Pasha ${ }^{1,2}$ \\ ${ }^{1}$ Department of Radiology, Faculty of Medicine, University of Prishtina "Hasan Prishtina", Pristina, Kosovo; ${ }^{2}$ Clinic of Radiology, \\ University Clinical Center of Kosovo, Pristina, Kosovo
}

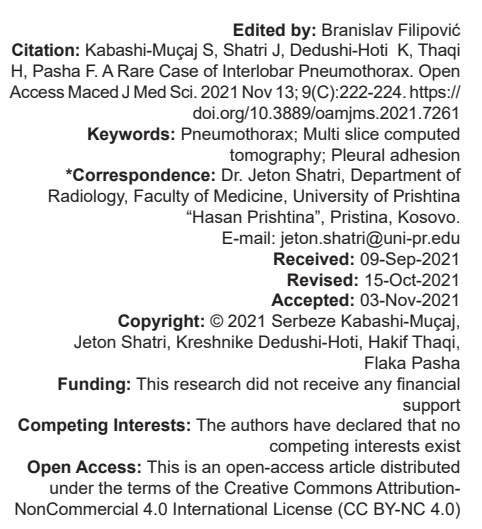

\begin{abstract}
BACKGROUND: Pneumothorax is a severe medical condition characterized by the collection of air in one or severa spaces of the pleura. A rare subtype of pneumothorax where air is restricted in interlobar pleural space, mostly due to the previous fibrous pleural adhesions, is known as interlobar pneumothorax.

CASE PRESENTATION: We present a rare case of a 58-year-old female admitted to the emergency department due to difficulty on breathing, hemoptysis, and discomfort in the right anterior axillary line, which worsened with inspiration and was associated with breathlessness during physical activity. The diagnosis was confirmed by thoracic multi slice computed tomography (MSCT), showing that air was located between the middle and lower lobes of the right lung, measuring $7 \times 5 \times 2.5 \mathrm{~cm}$ (transversal $\times$ oblique cranio-caudal $\times$ antero-posterior), representing interlobar pneumothorax.

DISCUSSION: Cases of interlobar pneumothorax need to be carefully differentiated and evaluated, while skin folds overlapping breast margin, interlobar fissure, bullae in the apices, pneumomediastinum, pneumopericardium, inferior pulmonary ligament air collection, pneumatocele, and air collection in the intrathoracic extrapleural space, can mimic pneumothorax and make diagnosing very challenging.
\end{abstract}

\section{Introduction}

Pneumothorax is a severe medical condition characterized by the collection of air in one or several spaces of the pleura. The British Thoracic Society Guidelines defines pneumothorax as an air space that is more than $2 \mathrm{~cm}$ from the pleural surface to the lung edge at the level of the hilum, on erect chest radiographs [1].

Pneumothorax is subdivided in: Primary pneumothorax which occurs in patients with no prior lung disease (associated with Marfan syndrome, Ehlers-Danlos syndrome, alpha1-antitrypsin deficiency, and homocystinuria); secondary pneumothorax appearing in individuals with cystic lung disease or parenchymal necrosis such as chronic obstructive lung disease, cystic fibrosis, lung cancer, catemenial pneumothorax, or pleuroparenchymal fibroelastosis; and traumatic or iatrogenic complications' pneumothorax such as after thoracentesis and positive pressure ventilation. In the other hand, the primary pneumothorax has been described also in exerted physical activities such as scuba diving, weight lifting, or even jogging [2], [3].

Primary spontaneous pneumothoraxes occur mostly in younger patients (typically $<35$ years of age), whereas secondary pneumothoraxes occur in older patients (typically over 45 years of age) [2], [3], [4].

The main clinical symptoms of pneumothorax are sudden chest pain, dyspnea, and dry cough. In pneumothorax, a one-way valve between the involved lung and the pleura leads to the continuous leakage of air into the pleural cavity and causes the accumulation of air within the pleural cavity. Thus, the ipsilateral lung collapses, the mediastinum is displaced away from the affected side, and the ipsilateral diaphragm is displaced downwards and may invert downwards. The cardiac output is reduced due to impaired venous return and cardiac arrest eventually occurs [4], [5].

Therefore, pneumothorax must be immediately treated with thoracic drainage. Conversely, patients with a small pneumothorax and without significant breathlessness are usually managed through clinical observation [6], [7].

\section{Materials and Methods}

We, hereby present a very rare case of spontaneous primary interlobar pneumothorax. 


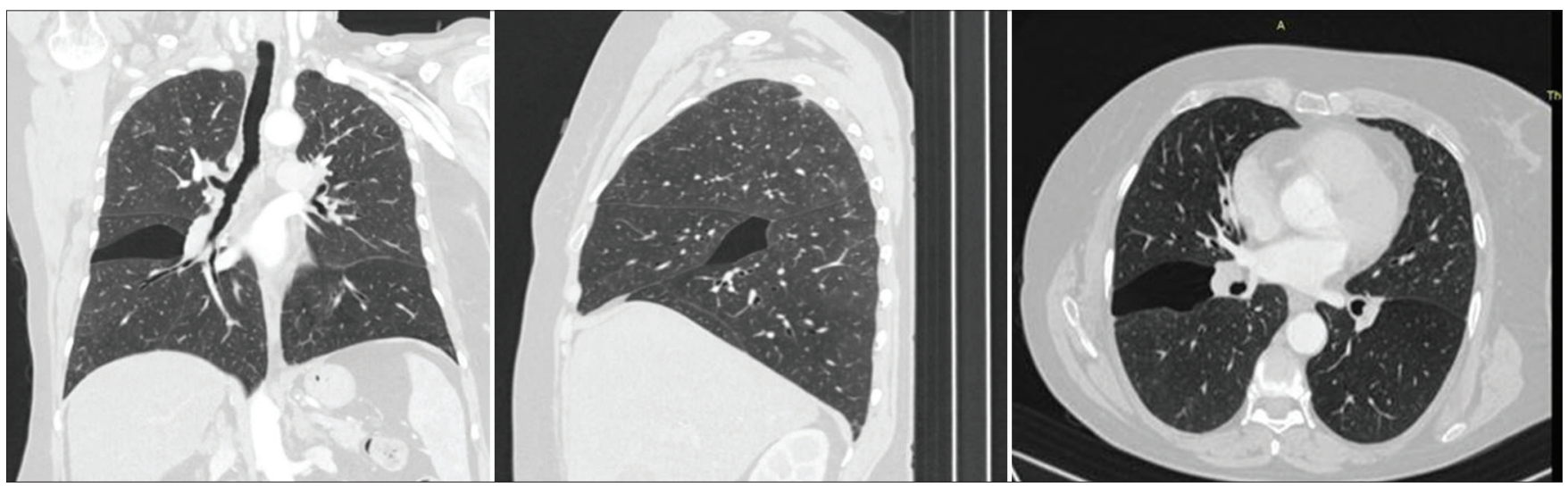

Figure 1: Multi slice computed tomography scan showing the right interlobar pneumothorax

A 58-year-old female patient presented to the emergency department due to difficulty on breathing and hemoptysis. She reported discomfort in the right anterior axillary line, which worsened with inspiration and was associated with a feeling of breathlessness during physical activity.

One month before emergency room admission, she had persistent cough and complained of the right chest pain during a jogging session. After the chest pain decreased, hemoptysis appeared, prompting her for medical advice. On arrival to emergency room, she was neither dyspnoeic nor cyanotic, but described the right chest pain during inspiration. Her body temperature measured $37.0^{\circ} \mathrm{C}$. Chest auscultation was normal, except for an axillary amphoric auscultatory sound. The patient was further referred from the pulmonologist to undergo chest radiography, suspected for the right lung infiltration.

\section{Results}

The frontal chest $X$-ray showed a circumscribed air-containing space. We noticed a thin, long, and linear opacity convex to the external part of the right chest, which had an indistinct superior end in the upper part of the chest. The pulmonary parenchyma external to this line was still in contact with the lateral chest wall. This line could be superimposed with the normal plane of the right inter lobar fissure. Lateral X-ray projections and standard tomography showed an oblong radiolucent area, instead of the normal right fissure.
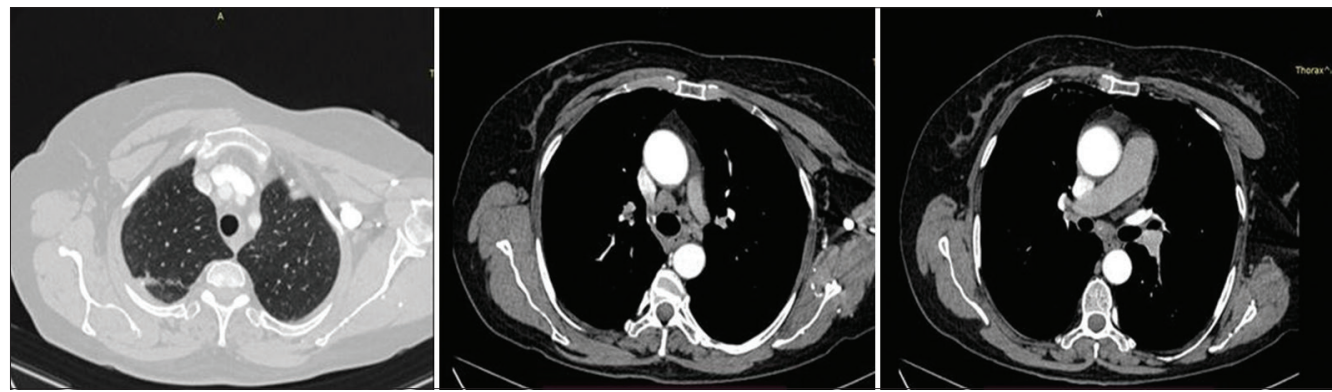

The diagnosis was confirmed by thoracic multi slice computed tomography (MSCT). CT scanning showed that there was air located between the middle and lower lobes of the right lung, measuring $7 \times 5 \times 2.5 \mathrm{~cm}$ (transverse $\times$ oblique cranio-caudal $\times$ antero-posterior). This case represents an interlobar pneumothorax, extending between the chest wall laterally and the right interlobar pulmonary artery medially. Vast majority of the air lies in the midst of the major fissure, but its upper portion also abuts the posterior aspect of the minor fissure (Figure 1).

Lungs otherwise appeared normal, except for a few fibrotic linear and nodular densities. There were few pre-tracheal and infra-tracheal lymphatic nodes depicted, of $14 \mathrm{~mm}$, respectively, $16 \mathrm{~mm}$. We found an incidental hyper vascular node on the left liver lobe, probably representing a metastatic lesion, primary hepatocellular carcinoma, or hemangioma (Figure 2).

With pulmonologist and chest surgeon's recommendations, patient was left untreated and only was followed for 3 consecutive months, when the pneumothorax retracted itself.

\section{Discussion}

Pneumothorax is almost always the result of rupture of an air-containing space into the visceral pleura. Air can come from a pneumomediastinum,

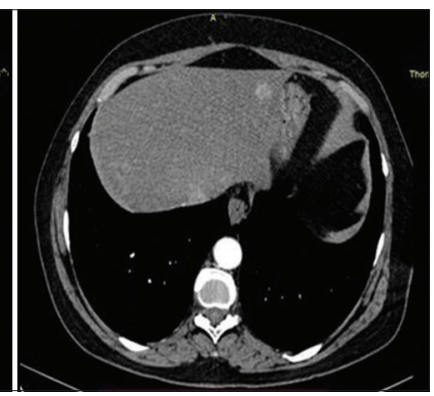

Figure 2: Incidental findings (fibrotic lung changes, mediastinal lymphatic nodes, and liver nodule) 
pneumopericardium, from a rupture of alveolar blebs or bullae, and from cystic spaces [8], [9].

Intra-fissured or interlobar restriction of the pneumothorax is due to the previous fibrous pleural adhesions. These before adhesions could be the result of pleurodesis or pleural diseases. Thus, pleural adhesions prevent air from spreading, as it generally does, into the pleural cavity. We cannot exclude the hypothesis that this particular form of interlobar pneumothorax may represent an incomplete resorption of a continuous complete pneumothorax. It is possible that old pleural fibrosis associated with bronchiectasis, localized the air to the adjacent interlobar fissure [2], [3], [10].

We want to also recall that in few cases of interlobar pneumothorax, a cystic appearance can develop with air-fluid level that can make the diagnosis even more challenging, requiring a great level of suspicion to avoid unnecessary interventions and harm patients [11], [12], [13].

\section{Conclusion}

Interlobar pneumothorax is a very rare medical condition, we encounter on our working routine. Therefore, we must be truly careful on its recognition, evaluation, and proper treatment. Many conditions, such as skin folds, overlapping breast margin, interlobar fissure, bullae in the apices, pneumomediastinum, pneumopericardium, inferior pulmonary ligament air collection, pneumatocele, and air collection in the intrathoracic extrapleural space, can mimic pneumothorax and need to be carefully differentiated and evaluated.

\section{References}

1. MacDuff A, Arnold A, Harvey J. Management of spontaneous pneumothorax: British Thoracic society pleural disease guideline 2010. Thorax. 2010;65(2):18-31.

2. Choi WI. Pneumothorax. Tuberc Respir Dis. 2014;76(3):99-104.

3. Bradnock TJ, Crabbe DC. Pneumothorax. In: Pediatric Thoracic Surgery. London, United Kingdom,: Springer; 2009. p. 465-80.

4. Roberts DJ, Leigh-Smith S, Faris PD, Blackmore C, Ball CG, Robertson $\mathrm{HL}$, et al. Clinical presentation of patients with tension pneumothorax: Asystematic review. Ann Surg. 2015;261(6):106878. https://doi.org/10.1097/SLA.0000000000001073. PMid:25563887

5. Bauman MH, Strange C, Heffner JE, Light R, Kirby TJ, Klein J, et al. Management of spontaneous pneumothorax: An American college of chest physicians delphi consensus statement. Chest. 2001;119(2):590-602. https://doi.org/10.1378/chest.119.2.590

PMid: 11171742

6. Schnell J, Beer M, Eggeling S, Gesierich W, Gottlieb J, Herth FJ, et al. Management of spontaneous pneumothorax and postinterventional pneumothorax: German S3 guideline. Respiration. 2019;97(4):370-402. https://doi.org/10.1159/000490179 PMid:30041191

7. Trump M, Gohar A. Diagnosis and treatment of pneumothorax. Hosp Pract 1995. 2013;41(3):28-39.

8. Bintcliffe OJ, Hallifax RJ, Edey A, Feller-Kopman D, Lee YC, Marquette $\mathrm{CH}$, et al. Spontaneous pneumothorax: Time to rethink management? Lancet Respir Med. 2015;3(7):578-88. https://doi.org/10.1016/S2213-2600(15)00220-9 PMid:26170077

9. Bintcliffe $O$, Maskell N. Spontaneous pneumothorax. BMJ. 2014;348:g2928. https://doi.org/10.1136/bmj.g2928 PMid:24812003

10. Grundy S, Bentley A, Tschopp JM. Primary spontaneous pneumothorax: A diffuse disease of the pleura. Respiration. 2012;83(3):185-9. https://doi.org/10.1159/000335993 PMid:22343477

11. Watanabe A, Shimokata K, Nomura F, Saka H, Sakai S. Interlobar pneumothorax. Am J Roentgenol. 1990;155(5):1135-6.

12. Watanabe A, Shimokata K. Interlobar pneumothorax. Ryoikibetsu Shokogun Shirizu. 1994;3:857-8.

13. Vincent $M$, Tourvielle $O$, Beguier $M$, Brune J. Interlobar pneumothorax. Rev Pneumol Clin. 1984;40(1):7-11. PMid:6718947 